\title{
RECENT INVESTIGATIONS ON RHEUMATISM AND ARTHRITIS IN THE UNITED STATES*
}

\author{
By PHILIP S. HENCH, M.D., \\ Division of Medicine, The Mayo Clinic, Rochester, Minnesota
}

THE incidence of "rheumatism and allied diseases" on a given day in the United States has been estimated"14 to be about one case ( 0.099 per cent.) per 1,000 persons. The incidence according to age and sex per 1,000 persons was as follows: less than $\cdot 05$ case among persons less than fifteen years of age; 0.9 among those aged fifteen to sixty-four years, and 5.4 for those aged sixty-five years or more. The incidence for females was twice that for males. In the arthritis clinic of the Presbyterian Hospital, New York, the percentage incidence of the commoner forms was about as follows: osteo-arthritis 30 , rheumatoid arthritis 25 , non-articular rheumatism 20 , traumatic and postural arthritis 10 , rheumatic fever 5 , gonorrhœal arthritis 3 , gout 1 , miscellaneous 6.45

\section{Gonorrhæal ARthritis}

Despite efforts of national and civic bodies there is as yet no significant reduction in the incidence of gonorrhœa in the United States. According to a recent survey ${ }^{115}$ the incidence per 1,000 population varied from a maximum of 46.6 white males, 69.9 negro males, 15.1 white females and 46.5 negro females to a minimum of 2.3 white males, 6.6 negro males, 0.2 white females and $2 \cdot 2$ negro females in various American localities. The incidence of gonorrhœal arthritis among cases of gonorrhœa is generally considered to be about 2 or 3 per cent.

Diagnosis.-The frequency and diagnostic significance of certain lesions of the skin which may accompany gonorrhœa and gonorrhœal arthritis have been emphasised again. ${ }^{54.61}$ The lesions include petechiæ and small red sore spots sometimes with a central white necrotic region. "The clinical lesion in full development is a hæmorrhagic, purulent vesicle or bulla, surrounded by a more or less broad erythematous areola." The hemorrhagic feature may be absent. Those concerned with

* Submitted for publication, February 24, 1940. 
diseases of joints should familiarise themselves with this lesion because it has been noted in cases of gonococcæmia and gonococcal arthritis, in which careful search revealed no culturally positive genital focus although gonococci were present in joints and in some of the cutaneous lesions.

In cases of chronic gonorrhœa cultures for gonococci are notably superior to direct smears, according to many investigators. But in 8 per cent. of one series of cases ${ }^{18}$ cultures were negative and smears were positive; hence both tests should be used when possible. Some physicians ${ }^{48}$ consider complement fixation tests superior to cultures or smears, but others ${ }^{50}$ have concluded that the fixation test as generally performed is of limited usefulness and needs further refinement and standardisation.

Treatment.-The two most effective remedies continue to be fever therapy and sulfanilamide or allied compounds used alone or together. Results of fever therapy in about 560 cases of gonorrhœal arthritis were reported. ${ }^{45}$ Complete cures were obtained in 70 to 90 per cent. of acute cases and in about 60 to 80 per cent. of chronic cases. From two to four, sometimes six to eight, sessions of fever were given, most of them consisting of five or six, occasionally seven, hours at 106 to $107^{\circ} \mathrm{F}$. (rectal) given every two to four days. With fever therapy, cures were obtained eleven times as often as with older methods (local chemotherapy, physical therapy) in cases of acute gonorrhœal arthritis, and six times as often in chronic cases. ${ }^{92}$ Fever therapy generally controlled both the articular and genital infections; but sometimes the latter were resistant; hence several physicians ${ }^{9.59 .82}$ favoured the use of fever combined with pelvic diathermy and reported prompt clinical and bacteriologic cures often after the use of only one ten-hour session.

Fever therapy, given in a hospital by a trained staff, is essentially safe. During the administration of about 5,700 sessions of fever therapy to more than 1,200 patients, only two deaths occurred. ${ }^{57.59,112}$ A few other untoward reactions were noted: minor burns, abdominal pains, cardiovascular collapse and two additional deaths, one of which was the first reported among children. ${ }^{34}$ Despite its effectiveness fever therapy is admittedly a time-consuming, uncomfortable and strenuous ordeal, a procedure available to only a small percentage of gonorrhœal patients. Hence it should be reserved for those whose disease is not amenable to the newer chemotherapeutic agents. 
Among the scores of papers ${ }^{45}$ on the effect of sulfanilamide on gonorrhœa which were reviewed for this synopsis were data on only fifty-four cases of gonorrhœal arthritis: in thirty-eight (70 per cent.) of these fifty-four cases the arthritis was rather promptly cured; in sixteen cases (about 30 per cent.) it was unimproved, or improved but not completely cured by the drug. One report ${ }^{7}$ was concerned with the treatment of fourteen patients with proved, and four with " probable," gonorrhœal arthritis with "large doses" of the drug (daily dose, $\frac{3}{4}$ grain or $0.05 \mathrm{gm}$. per pound of body weight, but not more than 120 grains or $8 \mathrm{gm}$. in one day). Nine (64 per cent.) of the former and two (50 per cent.) of the latter patients, that is, 61 per cent. of the total, were "strikingly improved" forty-eight to seventy-two hours after treatment was begun. Infected synovial fluids became sterile promptly, and no gonococci were present in genital foci after three days of medication. No relapses occurred. The effective dose varied greatly: some cures were effected with $5 \mathrm{mg}$. per cent. of free sulfanilamide in blood; in other cases $10 \mathrm{mg}$. per cent. or more was required. If definite clinical improvement was not noted seventy-two hours after starting "large doses," the doses were increased. To maintain a constant level of free sulfanilamide in blood, one-sixth of the total daily dose was given every four hours, day and night, and the fluid intake was kept constant.

Doses of sulfanilamide used by others in the treatment of gonorrhœal arthritis were: in one clinic, ${ }^{95}$ daily, 80 grains $(5 \cdot 2 \mathrm{gm}$.) for two days, 60 grains $(4 \mathrm{gm}$.) for two days, and 40 grains $\left(2.6 \mathrm{gm}\right.$.) for seven days; in another clinic, ${ }^{25}$ daily, 75 grains ( $5 \mathrm{gm}$.) for two to three days, 60 grains $(4 \mathrm{gm}$.) for two to three days, then 40 grains $(2 \cdot 6 \mathrm{gm}$.) for the remainder of a fourteen-day course. Although the full doses originally recommended by Long (1937) and by Colston, Dees and Harrill (1937) were used occasionally, in most cases gonorrhœa and gonorrhœal arthritis were treated by smaller doses. The true value of sulfanilamide in the control of gonorrhœal arthritis can be determined only by treating with full doses many more patients who are known to have gonococci intra-articularly.

A statistical summary of forty-six recent reports on the use of sulfanilamide for urogenital gonorrhœa was made. ${ }^{45}$ Of 2,293 cases of gonorrhœa noted therein, cure was presumably effected in 67 per cent. (1,540 cases). Many of the patients were 
ambulatory and were not subject to as close supervision, nor as tolerant of full doses of the drug, as hospitalised patients. Among the reasons for failure to obtain cures in some cases were the inability of about 10 to 20 per cent. of patients to take adequate amounts of the drug, use of insufficient doses for those who could take full doses, premature cessation of treatment, stopping of medication when symptomatic cure resulted but before bacteriologic cure was obtained, and the resistance of certain patients, or their strains of gonococci, to sulfanilamide. In general, however, dramatic results and very prompt and satisfactory cures were noted. Therefore it seems probable that regardless of whether the incidence of genital gonorrhœa is notably reduced or not, the incidence of gonorrhoal arthritis will be markedly lowered as more and more patients are given sulfanilamide or allied compounds early. In a series of papers which concerned about 2,247 cases of gonorrhœea treated with sulfanilamide, mention was made of only thirty-one cases of gonorrhœal arthritis: the expected incidence of gonorrhœal arthritis among that number of cases of gonorrhoea (at a rate of three per 100 cases) should have been sixty-seven instead of thirty-one cases. This observation suggests that already the incidence of gonorrhœal arthritis has been notably reduced, and is the basis for the, perhaps unduly optimistic, prediction of some physicians that gonorrhœal arthritis may practically disappear.

This type of treatment has many advantages: the drug is cheap, easy to use and essentially non-toxic, and it promptly cures about 70 per cent. of patients with gonorrhœal arthritis, even though it must often be given to ambulatory patients for whom the dosage cannot be controlled satisfactorily. Its disadvantages, however, are becoming more obvious. It provokes annoying reactions commonly, and serious, even fatal, reactions occasionally. ${ }^{45}$ Effective doses cannot be taken by 10 to 20 per cent. of patients, and it has failed to cure in about 30 per cent. of cases of gonorrhœal arthritis. Therefore several physicians ${ }^{45}$ have combined the use of sulfanilamide with older forms of local chemotherapy or with fever therapy. In a number of cases, gonorrhœal arthritis, which had proved resistant either to fever therapy or to sulfanilamide when used alone, was cured promptly by the combined form of treatment.29.88.95 Some physicians ${ }^{20}$ prescribed 80 grains $(5 \cdot 2 \mathrm{gm}$.) of the drug daily for two days prior to fever therapy (generally one ten-hour session at $106^{\circ} \mathrm{F}$.). 
Others ${ }^{95}$ gave 40 grains $(2 \cdot 6 \mathrm{gm}$.) of the drug daily for three days, then ten hours of fever at $106^{\circ} \mathrm{F}$. or 60 grains $(4 \mathrm{gm}$.) the day before a fever session of seven hours at 104 to $105^{\circ}$ F..$^{5}$ It was recommended ${ }^{25}$ that patients who are not relieved of gonorrheal arthritis by three to six days of treatment with sulfanilamide should be promptly subjected to fever therapy.

\section{Tuberculous Spondylitis}

Do fusion operations shorten the course of tuberculous spondylitis and prevent deformity? After making a careful, " unprejudiced" ten-year study, a group of physicians ${ }^{33}$ answered this question in the negative. One group of twenty-six patients was treated by fusion operations, generally of the Albee type. Another group of seventeen patients, closely parallel as to age and the duration, severity and situation of their disease, received conservative measures: rest on frames, good food, sunlight, fresh air, and so forth. The surgical group required 40 per cent. more time (average, 1,215 days) for cure than the non-surgical group (average, 876 days). The operation seemed to prolong, rather than shorten, the course of the disease. Despite firm fusion the disease in the vertebræ seemed uninfluenced: in each group about the same number of abscesses, paraplegias, recurrences and spinal deformities developed.

\section{Pneumococcal Arthritis}

Pneumococcal arthritis, a rare disease, will probably become rarer as a result of the use of the newer sulfonamide compounds. No instance of pneumococcal arthritis was noted among the numerous cases of pneumococcal infections so treated and reviewed for this report. ${ }^{45}$

\section{SyPHILIS OF JoINTS}

"Arthralgia" develops in about 5 to 10 per cent. of cases of early syphilis; syphilitic synovitis or arthritis in about 1 per cent. The commonest form is "Clutton's joint," bilateral synovitis with hydrops of knees among congenital syphilitics. ${ }^{68}$ Syphilitic synovitis occurs more often in late cases of acquired syphilis. For it synovectomy was considered useful. Gummatous arthritis occurs only in tertiary syphilis; according to some $^{96}$ it may closely resemble rheumatoid arthritis, an idea not concurred in by others. ${ }^{68}$ In about 4 per cent. of cases of 
tabes Charcot joints develop; new cases were described.45 An improved technic for arthrodesis of Charcot joints was described : ${ }^{98}$ multiple bone drillings of involved articular bones to improve vascularity and osteogenesis; immobilisation for four to six weeks by a posterior plaster splint; then standard arthrodesis.

\section{Brucellosis: Undulant (Malta) Fever}

Symptoms Referable to Muscles and Joints.-It is agreed that " joint pains," "pains in limbs," "rheumatic pains in back and joints" and "pains in muscles of arms and legs" are common features of brucellosis, but there is no agreement as to the incidence of true acute or chronic arthritis from brucellosis. Brucellosis is particularly common in the south-western part of the United States, and certain physicians ${ }^{35.69 .85}$ there have reported that the disease commonly masquerades as rheumatoid arthritis. Physicians elsewhere are inclined to believe that most of these cases probably represent ordinary rheumatoid arthritis coincidentally present in cases of latent, sometimes of active, brucellosis.

Diagnosis.-Opinions still differ as to which of the various laboratory tests is most helpful in diagnosis; in general the agglutination test was favoured. ${ }^{45}$ A negative result, however, does not prove the absence of the disease; in almost half of one series of chronic cases negative reactions were obtained. Certain experiments ${ }^{117}$ indicated that sulfanilamide markedly increases opsonocytophagic activity for Brucella organisms, and in some cases of brucellosis agglutination tests gave negative results before administration of sulfanilamide and positive results afterward.

Treatment.-Results of the use of serums, typhoid vaccine and certain "specific vaccines" seemed satisfactory to some physicians, unimpressive to others. ${ }^{45}$ In 81 per cent. of twentyone cases of brucellosis in which treatment consisted of artificial fever (five to twenty-two hours) cure occurred, ${ }^{81}$ but sulfanilamide appears to be the most promising remedy. Striking recoveries followed its initial use by eight patients treated in Europe, some of whom may have been entering a period of remission or recovery when treatment was begun. The further experience of American clinicians confirms that of English workers and seems to indicate that the drug is truly effective. Twenty recent reports ${ }^{45}$ gave results from the use of the drug in sixty cases of acute and chronic brucellosis: 87 per cent. of the patients were "cured" 
generally within four to seven days. Usually the drug was given orally in doses ranging from 60 to 75 grains (4 to $5 \mathrm{gm}$.) daily for about nine days, to 35 grains $(2 \cdot 3 \mathrm{gm}$.) daily for about ten days.45.111. 117 Because relapses occurred occasionally, some physicians advised the routine use of one to three follow-up courses, each a week long, within two or three months of " a cure."

\section{Meningococcic ARthritis}

The incidence of articular lesions in meningococcic infections has varied from 4.8 to 20 per cent. in different epidemics; it was recently 7.7 per cent. at Bellevue Hospital, New York. Details of twenty-three new cases were reported. ${ }^{90}$ Articular lesions were classified thus: (1) An early, often pre-meningitic, polyarthritic or arthralgic form attributable to peri-articular and intra-articular petechial hæmorrhages in which the general prognosis is poor and that of joints is good; (2) the usual post-meningitic form, which generally appears after the fifth day of the general infection, is purulent and may produce irreparable articular damage; (3) a serous type resembling serum sickness; and (4) occasional postmeningitic spondylitis which may represent a true meningococcal entity, or in some cases may result from damage to discs from repeated spinal puncture.

Articular lesions were treated by aspiration, splinting and occasionally by traction. The general infection was treated by serum and Hoyne's antitoxic-antiserum, or by sulfanilamide. The latter seemed to be as effective as, in some cases more effective than, serum. Among 205 patients with meningococcic meningitis (none with arthritis) recently treated by sulfanilamide alone or in combination with serum there were only seventeen deaths. ${ }^{45}$

\section{Articular Disease caused by Hamolytic Streptococci}

Formerly a fairly large proportion of cases of septic arthritis was due to hæmolytic streptococci, but since the advent of sulfanilamide this type of septic arthritis already seems to be disappearing. Only one instance of this complication was noted among many recent reports of conditions attributable to these bacteria: perfect function was obtained in a septic knee after use of sulfanilamide and aspiration. ${ }^{17}$ This illustrates the supreme importance of making bacteriologic diagnosis as often and as early as possible in all cases of acute (septic) arthritis. 
Arthritis of Scarlet Fever: Post-scarlatinal Rheumatism

Opinions vary as to the value of sulfanilamide in scarlet fever; some say that it has no effect on fever, toxæmia or incidence of complications, but others ${ }^{89}$ noted a reduction in the incidence of arthritis in patients given the drug.

\section{Rheumatic Fever}

Clinical Data.-Noted in one group of rheumatic patients was a familial tendency manifest for at least three generations which strongly suggested constitutional susceptibility to the disease. $^{84}$ Rheumatic symptoms affected four times as many siblings, four times as many parents, twice as many uncles and aunts, and eight times as many grandparents of thirty-three rheumatic children as they did those of thirty-three non-rheumatic children. Within two weeks each of identical twins came down with rheumatic fever and mitral endocarditis. ${ }^{73}$ Rheumatic fever frequently may attack children earlier than has been suspected: in the fatal case of an infant thirty-two months old, the disease apparently began at the age of eighteen to twentyfour months. ${ }^{28}$

Clinical data on new series of cases were reported.4,63 Polyarthritis and carditis respectively affected 135 and 122 of one group of 150 patients whose average age was eighteen years. ${ }^{4}$ An unusual complication in one fatal case was rectal temperature of $109^{\circ}$ F.12 In Philadelphia in 1936 the mortality rate for rheumatic carditis was $17 \cdot 6$ per 100,000 population when "probable cases" were excluded and about 25 to 30 per 100,000 population when they were included. The mean age at death was 36.5 years. ${ }^{40}$ The incidence of rheumatic carditis among 104,163 students at eighty-six American colleges and universities was 11.6 per $1,000(9.5$ per 1,000 men, 14.9 per 1,000 women $){ }^{39}$ Calcareous aortic stenosis occurs much more frequently than has been supposed, and is unquestionably a rheumatic lesion.22, 119 The argument on the specificity of subcutaneous rheumatic nodules has continued. One investigator, ${ }^{67}$ using supravital stains, regarded the nodules as very similar to, if not identical with, nodules from patients with rheumatoid arthritis, but another physician ${ }^{55}$ noted enough differences for him to differentiate them. Physicians agree on the type of pathologic reactions 
found in lungs, but disagree as to whether or not they are specific for rheumatic fever: one writer ${ }^{70}$ considered the pulmonary reaction not of the simple inflammatory type (bacteria and necrosis are absent) but a hyperergic one; another writer regarded "rheumatic pneumonia" as possibly an important factor in subsequent failure of the right ventricle. ${ }^{36}$ A thorough review of rheumatic erythema appeared. ${ }^{55}$ Contrary to older opinions, erythema annulare rheumaticum may occur as an initial symptom of rapidly fatal rheumatic fever. ${ }^{3}$ Recent literature has included descriptions of a variety of so-called rheumatic abdominal symptoms. ${ }^{27}$ Their significance will be uncertain until a pathologic explanation for them is forthcoming. New statistical studies were made on the course of rheumatic fever and on the manner of death therefrom; unfortunately they afforded no grounds for lessening one's pessimistic attitude toward this disease. ${ }^{11 .} 13,51$

Laboratory Data.-It was noted that hypocholesterolæmia accompanies acute rheumatic fever and rheumatic carditis frequently, but not always. ${ }^{75.78}$

AEtiology.-Further data have been suggestive of, but have not proved, a relationship between rheumatic fever and nasopharyngeal infections caused by hæmolytic streptococci. ${ }^{45}$ The hypothesis of bacterial allergy as the cause of the disease is accepted by some, severely criticised by others. Further evidence was reported $53,87,94$ indicating that patients with active or quiescent rheumatic fever have subnormal amounts of vitamin $\mathrm{C}$ in their serum, but it is difficult to interpret these data: it is possible that most rheumatic patients are simply on a deficient diet, or that the disease depletes their blood of the vitamin, and the deficiency, therefore, is the result, not the cause, of the disease; $; 4$ or that the deficiency represents an inherent or acquired metabolic fault which may be an integral factor in the causation of the disease. ${ }^{87}$

Treatment.-There have been no outstanding new developments in treatment. Despite the supposed relationship between rheumatic fever and hæmolytic streptococci, sulfanilamide seems to have no beneficial effect on the course of any features of the disease. Two groups of eight and fifty-eight patients in all stages of the disease were treated. ${ }^{66,102}$ No benefits were noted; indeed, symptoms were often intensified and marked toxæmia was noted. Sulfanilamide may prove more useful in the pre- 
vention of rheumatic exacerbations due to acute hæmolytic $\frac{D}{\omega}$ streptococcal pharyngitis than in the treatment of the disease. Following the use of neoprontosil, throat cultures of carriers of hæmolytic streptococci frequently became negative. ${ }^{46}$ Of special interest are two reports ${ }^{23,107}$ concerning 110 rheumatic patients who received from 15 to 30 grains ( 1 to $2 \mathrm{gm}$.) of sulfanilamide daily from November to June: hæmolytic streptococcal infection and significant rheumatic exacerbation developed in only one case; controls were more frequently affected. No notable reaction to the drug occurred.

Tonsillectomy and the use of vaccines and serums continue to yield equivocal results. ${ }^{45}$ Use of vitamin $\mathrm{C}$ does not prevent or cure the disease, ${ }^{53}$ but the increased need of rheumatic patients for this vitamin should be recognised and supplied. Fever 9 therapy seemed to reduce symptoms and shorten the attacks in a few cases. ${ }^{95}$ It did not harm the heart; indeed, cardiac improvement seemed to occur in some cases, ${ }^{76}$ but the patients have not been observed long enough to note whether the course of the carditis was really affected.

\section{Sydenham's Chorea}

For a century a close relationship generally has been thought to exist between chorea and rheumatic fever, but just what the relationship is has been solved by neither bacteriologic nor pathologic researches. According to some, no structures resembling rheumatic nodules have been found at necropsy in cases of pure chorea; but one physician recently noted perivascular nodules resembling Aschoff bodies in the brains of patients dead of chorea. ${ }^{93}$ Because of the frequency with which pain of muscles and joints, frank rheumatic attacks and carditis developed among 467 patients with chorea, other physicians ${ }^{100}$ regarded chorea 9 not only as a manifestation, but a major manifestation of rheu- $\frac{D}{\square}$ matic infection.

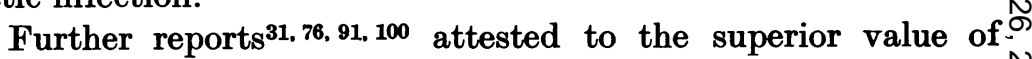
fever therapy for this disease. One group of ninety-nine choreic $\stackrel{N}{\sim}$ children, given fever therapy, thereafter had polyarthritis much less frequently, carditis and recurrent chorea somewhat less frequently than did a group of sixty-six choreic children treated $\bar{\Phi}$ otherwise. ${ }^{100}$ Sulfanilamide was valueless in the treatment of $\stackrel{\text { ? }}{?}$ seven cases. ${ }^{66}$ 


\section{Rheumatoid (Atrophic) Arthritis}

Clinical Data.-Details concerning three new series of cases were reported.15,60.110 Among 1,765 patients with rheumatoid arthritis shoulders were affected in only 9 per cent. ${ }^{60}$ Symptoms referable to the shoulders were out of proportion to roentgenographic changes, which were rarely marked. Rheumatoid arthritis of shoulders tends to be bilateral; it usually progresses slowly, generally without the exacerbations which affect weight-bearing joints, and often almost painlessly, to a stage of marked limitation unless early vigorous treatment is instituted.

Attention is being paid to two special clinical features, the effect of jaundice ${ }^{41.108}$ and of pregnancy ${ }^{42,45}$ on rheumatoid arthritis. Coincident with the development of intra-hepatic or obstructive jaundice, remissions in articular symptoms occurred in nineteen cases and lasted from five to eighty-two weeks. (Remissions lasting from four to 104 weeks occurred in nine cases of primary fibrositis and jaundice.) Relief of pain was complete in 63 per cent. of the arthritics, in all of the fibrositic cases; relief was notable but incomplete in 37 per cent. of the arthritic cases. Active articular swelling, muscular stiffness, soreness and fatigue also were reduced markedly or had disappeared, but residual articular thickening and stiffness from deformity were of course unaffected. As one person said, "When the jaundice came in the front door, the rheumatism went out the back door." The duration and completeness of remissions bore a general, but not a specific, relation to the intensity and duration of jaundice. Mild jaundice was ineffective. The phenomenon was evoked in rheumatoid arthritis by several types of jaundice, but it was not evoked when jaundice affected patients with certain other painful types of articular and neuritic diseases. Apparently in rheumatoid arthritis the phenomenon usually does not, but occasionally may, accompany jaundice from chrysotherapy. ${ }^{45}$

Pregnancy has long been considered dangerous for arthritic women because disease of the joints is likely to flare up after parturition. Physicians ${ }^{42,45}$ recently have concluded that, regardless of the aftermath, pregnancy, like jaundice, initiates a physiologic state decidedly beneficial, at least temporarily, to patients with certain articular diseases, notably rheumatoid arthritis. The effects of thirty-seven pregnancies on twenty-two 
patients (sixteen with rheumatoid arthritis, two with psoriatic arthritis, two with peri-articular fibrositis, one with intermittent hydrarthrosis and one with localised lumbar arthritis, presumably infectious) were studied. Twenty of the twenty-two patients obtained marked, generally complete, relief of articular symptoms during pregnancy and for variable periods thereafter. These twenty patients had thirty-four pregnancies, in thirty-three of which the phenomenon of relief appeared; it did not appear in a case of early tubal pregnancy, nor did three pregnancies favourably affect the arthritis of two additional women. With variations, the remissions generally began about the fourth week of pregnancy and lasted about four to six or more weeks. after parturition. Several patients noted relief on repeated pregnancies, in one case during each of nine pregnancies. ${ }^{45}$ It seemed reasonable to suppose that the agents responsible for both of these phenomena (relief from pregnancy and from jaundice) are closely related, perhaps identical. "If the potent common denominator of these two phenomena can be discovered, progress in treatment may be expected." Meanwhile it becomes obvious that rheumatoid arthritis (and fibrositis) can no longer be regarded as necessarily relentless, uncontrollable diseases for which no rapid method of control should ever be expected. The pathologic physiology of these diseases is apparently rapidly reversible. It behoves physicians to learn how to stimulate in a practical way the beneficial mechanism so effectively stimulated temporarily by jaundice or pregnancy.

Instances of three features rarely associated with rheumatoid arthritis were reported :45 " opera glass hand " (la main en lorgnette of Marie and Leri), scleromalacia perforans and diabetes with resistance to insulin.

Pathology.-The focal collections of round cells commonly seen in synovial membranes in rheumatoid arthritis are considered by some to be specific for this disease, by others to be non-specific. Recent writers ${ }^{47.52}$ favoured the latter view.

Laboratory Data.-Arguments for and against the infectious theory were summarised.44 The rôle of infected foci has not been clarified. 'A former strong advocate of focal removal reported ${ }^{20}$ his discouragement at the results thereof: of his 200 consecutive patients with rheumatoid arthritis, 70 per cent. had no demonstrable foci, 10 per cent. had doubtful foci, only 20 per cent. had definite foci, and only a few patients were improved 
by removal of the definite foci. "As far as typical rheumatoid arthritis is concerned, it would appear that chronic focal infection plays a comparatively unimportant rôle." Others took a less positive stand. ${ }^{45}$ Still others ${ }^{77}$ repeated their view that many of the symptoms of this disease arise from disturbances of peripheral circulation and can be alleviated by correction of the latter. Some physicians ${ }^{86} 94$ continue to regard a deficiency of vitamin C as an important ætiologic factor, but have adduced no conclusive evidence thereof.

Treatment.-The conservative removal of obviously infected foci was generally recommended, not as a cure, but to improve the patient's general health. Vaccine therapy seems to be finding fewer champions; good results were noted by some physicians, but the majority considered vaccines of very limited value. Injections of chaulmoogra oil found little favour. ${ }^{45.97}$ Bee venom therapy received only faint praise, ${ }^{58}$ and results from actual bee stings were " discouraging." 74 "Encouraging," but not striking, were the results from the intravenous and oral administration of ascorbic acid. ${ }^{86}$ Massive doses $(80,000$ to 160,000 U.S.P. units) of vitamin $D$ were given daily to two groups totalling forty-seven patients; the majority were not improved; a few noted transient subjective improvement.2. 99

Chrysotherapy is being investigated in several research clinics, but reports of results are not yet generally available. In one series of cases ${ }^{110}$ preliminary results were " disappointing," but no details were given. Others ${ }^{56}$ considered chrysotherapy of distinct value. Sulfanilamide has proved to be valueless.7.95

Various attempts have been made to reproduce the analgesic effect of spontaneous jaundice by using bile and related substances. No significant results were noted by one physician ${ }^{41,43}$ from the use of natural or synthetic bile salts, human bile, ordinary liver extracts, transfusions of jaundiced blood and experimental jaundice induced by toluylenediamine. Other physicians ${ }^{108 .} 109$ observed no beneficial effect from the intravenous use of either bile salts (decholin) alone or bilirubin alone, but they reported that injections of the two together in fairly large doses daily for seven to twelve days produced an ameliorating effect. Of sixteen patients so treated fourteen experienced variable amounts of relief lasting from only a few days to several months. Elsewhere, ${ }^{43}$ however, the work could not be satisfactorily corroborated. Twelve patients received from twelve to thirty daily intravenous 
injections of bilirubin and decholin. Despite the production of a notable pigmenting hyperbilirubinæmia, little or no relief was noted in five cases, short incomplete remissions resulted for a few days only in six cases; one patient had a rather complete remission of symptoms lasting only three weeks. The procedure is still experimental, but the fact that the disease could be modified at all by such a novel method seems significant. The matter deserves further consideration.

\section{StIIL's Disease}

Clinical and pathological features were reviewed.45,80,105 In only about twenty cases have data obtained at necropsy been reported; such data concerning several new cases were noted.

\section{Primary Osteo-arthritis}

"Osteo-arthritis of the same type seen by every radiologist today" affected the bones of a mastodon of the Post-Pleistocene Age recently found in North Carolina. ${ }^{21}$

AEtiology.-Recent discussions on ætiology were mostly restatements of the usual ideas, and no striking new evidence for any one theory was presented. Metabolic rates are generally normal ${ }^{83}$ concentrations of vitamin $\mathrm{C}$ in blood are not deficient. ${ }^{86}$

Treatment.-When a patient learns that he does not have a seriously crippling, ankylosing disease, " he will go home greatly improved because you have dispelled his fears." 118 The usual remedies are recommended:45 rest, reduction of trauma, dietary correction of obesity, physical therapy and, in selected cases, peri-articular and intra-articular injections of 1 per cent. procaine hydrochloride. ${ }^{104}$ Despite its apparent inappropriateness in this disease, synovectomy reputedly gave surprising relief to twenty patients with knees which were "painful and disorganised" by osteo-arthritis. ${ }^{47}$ Most workers ${ }^{45}$ considered massive doses of vitamin $D$, removal of foci, injections of vaccines or chaulmoogra oil and fever therapy of little value.

\section{Backache and Sciatica}

The usual multitude of papers were concerned with the manifold causes of backache. ${ }^{45}$ Detailed anatomic and clinical studies were made of the finer anatomy of the sacro-iliac joints. Basing his opinion thereon, one writer ${ }^{37}$ concluded that in cases of acute and chronic sacro-iliac pain lumbar and sacral joints are "not subluxated nor slipped, but roughened by infection and impacted or locked at one extreme of the normal slight but real motion." 
Manipulation was considered the best treatment; its technique was described. The clinical and laboratory features of ruptured intervertebral disc and methods for its diagnosis were again reviewed in a score of papers ${ }^{45}$ concerning more than 200 new cases proved at operation. Several of the papers ${ }^{6,8,32,64,79}$ were of special interest. Characteristic features were a history of trauma to the back (in 50 to 80 per cent. of cases), sudden or insidious appearance of low back pain, generally (in 92 per cent. of cases $^{64}$ ) with sciatica. The latter was unilateral in about 80 per cent., bilateral in about 20 per cent. of cases, and was constant or intermittent. Symptoms also included kyphos or flat back, scoliosis, reduced Achilles reflex, sometimes sensory and motor changes. Diagnosis is made on evidence derived from spinal fluid (generally elevation of protein above $40 \mathrm{mg}$. per cent.) and spinograms made after injections of air or lipiodol. Laminectomy and removal of the protruded disc were successful in practically all reported cases. Recurrences of pain were few; post-operative deaths were rare. Hypertrophied ligamenta flava may produce symptoms and signs similar to those from ruptured discs; $;^{3}$ the two conditions cannot be differentiated even by spinograms. This is immaterial as the treatment of both involves laminectomy. Successful results from removal of the enlarged ligaments in fifteen new cases were reported.45 Details of 583 cases of lumbar spondylolisthesis were reported. ${ }^{72}$

An interesting association was reported ${ }^{62}$ between sciatica, hepatic disease and jaundice. Five cases of "sciatic neuritis" were described which preceded the onset of hepatitis; when jaundice developed, the sciatic pain was completely or almost completely relieved.

\section{SPONDYLITIS}

Spondylitis Osteo-arthritica.-An unusual case was described, that of a man aged fifty-six years with marked cervical osteoarthritis and extensive bilateral ossification of stylohyoid ligaments.19 Hanflig's (1936) method of treatment for cervical osteo-arthritis, repeated mechanical stretching of the neck, received further approval: "some measure of relief" was noted by all of ten patients so treated. ${ }^{106}$

\section{Gout and Godty Arthritis}

Clinical Data.-Current literature might lead one to the belief that gout is leaving its old homestead in England and is catching 
up with the descendants of the Pilgrims in the United States. With relative ease American clinicians on the alert for gout have collected an appreciable number of cases of classical gout within a short time. The hereditary factor remains elusive; it was present in only 10 per cent. of one series of cases. ${ }^{24}$ As usual most patients were men, but women with classical tophaceous gout were seen.103, 116 Two American negroes were affected. ${ }^{16 .} 24$ New data on the medicinal provocatives of gout were reported; acute attacks were said to be precipitated by thiamin chloride (vitamin $\left.\mathrm{B}_{1}\right)^{116}$ and by decholin;14 salyrgan does not always provoke them..$^{49}$ Tophi affected 32 and 43 per cent. respectively of patients in two series. ${ }^{49.116}$ Of special interest was a case of severe tophaceous gout with flexion deformities of knees and fingers, and ankylosis of multiple joints; the condition somewhat resembled rheumatoid arthritis. Gout was the sole cause as demonstrated by pathologic examinations. ${ }^{65}$ Data currently presented favouring the existence of irregular gout continue to be unconvincing. ${ }^{45}$ Renal insufficiency affected 33 per cent. of twenty-one cases;49 urate stones and gravel were not infrequent complications, and were occasionally discovered before the first attack of gouty arthritis. ${ }^{103}$

Laboratory Data.-Not sufficiently known is the fact that sedimentation rates are markedly elevated in many cases (but not always) during acute attacks and rapidly become normal thereafter. ${ }^{45}$ It was again noted that the uric acid of whole blood was usually, but not always, elevated, and the pattern of hyperuricæmia bore no constant relationship to that of the gouty arthritis. One investigator ${ }^{49}$ noted that uric acid in serum (from blood collected and allowed to clot under oil) is constantly higher and less variable than that in whole blood; tests on serum were therefore recommended as being more accurate.

Pathological Features.-Excellent studies on the pathology of gout were made on the case which resembled rheumatoid arthritis, and the findings were described in detail by word and microphotographs. ${ }^{65}$ The ankylosis was caused by extensive formation of pannus studded with urates.

Attiology and Pathogenesis.-No new ideas on ætiology were reported. No evidence was found ${ }^{103}$ to support the ideas that the hyperuricæmia results from a deficient excretion or diminished destruction of urates in the body. Several gouty patients both during and between attacks excreted more urates than did non- 
gouty controls. Cyclic variations occurred not only in the excretion of urates but also in urinary volume and its chloride content, in body weight and in insensible loss of perspiration; these variations occurred among both gouty and non-gouty persons, but were more notable among those with gout. Changes in barometric pressure seemed to be related to these cycles.

Treatment.-A few additions to standard treatment were reported. Crystalline thiamin chloride (vitamin $\mathrm{B}_{1}$ ) was given orally and parenterally ( 1 to $10 \mathrm{mg}$.- that is, 330 to 3,300 international units-daily) to twenty-five gouty patients. In most cases an acute attack was provoked by initial doses, but thereafter the frequency of attacks was presumably lessened in several cases although hyperuricæmia was not controlled.116 Despite the older views of the inefficacy of colchicine as a prophylactic of acute attacks some physicians again are advocating its intermittent use between attacks as a substitute for cinchophen. ${ }^{34}$, 103

Uric Acid Problem.-By studying the offspring of Dalmatian hounds (" high uric acid excretors") mated with collies ("low uric acid excretors") it was found"13 that " high uric acid excretion" is inherited as an almost completely recessive, nonsex-linked character, dependent on the presence of a single pair of mendelising genes. The genes underlying the " high uric acid excretion" and those underlying the production of Dalmatian spotting are resident in independent pairs of chromosomes. Such studies could and should be carried out on gouty families, particularly on the offspring of the union of a gouty and a nongouty person. Children and other relatives of patients with gout may demonstrate notable hyperuricæmia without (other) symptoms of gout. ${ }^{49}$

\section{Psoriatic Arthritis}

The percentage incidence of psoriasis was $2 \cdot 6$ among 1,000 cases of rheumatoid arthritis, but only 0.3 among 1,000 cases of osteo-arthritis; ${ }^{26}$ hence the association of psoriasis and rheumatoid arthritis was considered " of real significance." Of the twentysix patients with psoriasis and rheumatoid-like arthritis, twelve had features sufficient for a diagnosis of "classical psoriatic arthritis." Two patients with psoriatic arthritis were markedly relieved of articular symptoms during pregnancy. ${ }^{42}$ Massive doses of vitamin $D$ (average dose 300,000 units) were given daily for five to thirty weeks to nineteen psoriatic patients, only two 
of whom had arthritis. Symptoms referable to the joints were not relieved, but the psoriasis cleared entirely in three cases, was markedly improved in seven, and unaffected in the rest. ${ }^{45}$

\section{Menopausal Arthralaia}

The characteristics of this condition as it affected fifty-three patients were described ${ }^{38}$ and included freedom from symptoms referable to the joints until after artificial menopause, then the appearance of articular pain, stiffness and tenderness without swelling or deformity, normal sedimentation rates, aggravation of menopausal symptoms by thyroid therapy and relief of menopausal and articular symptoms by estrogenic substance, generally 10,000 or more international units of progynon $B$ given intramuscularly twice weekly for several weeks.

\section{Articular Physiology}

By a modification of methods used to isolate chondroitinsulphuric acid from cartilage physicians ${ }^{71}$ obtained from synovial fluid a sulphur-free and phosphorus-free polysaccharide apparently identical with hyaluronic acid, the polysaccharide isolated from bovine vitreous humour, human umbilical cord and hæmolytic streptococci (Lancefield, group A). Its presence in the lastnamed seems significant in view of the possible relationship of these bacteria to diseases of joints. The theory was presented ${ }^{10}$ that normal calcification of bone is maintained by an alternating ischæmia and hyperæmia, produced by the contraction and relaxation of muscles. Hyperæmia causes rarefaction, decalcification of bone and osteoporosis; a relative ischæmia produces consolidation of bone. When the circulation is maintained within normal limits, bone remains unchanged. If hyperæmia produces resorption of bone, the use of heat in certain osseous and articular conditions may be injurious.

\section{Campaign against Rheumatism}

During the year under review the progress made in the campaign against rheumatism in the United States was considerable, even though unspectacular. Chief sponsors of the campaign in this country are the American Committee for the Control of Rheumatism, allied to the "Ligue internationale contre le rhumatisme," and the American Rheumatism Association. Of the international campaign Sir William Willcox recently wrote: "The 
movement has passed the dangers of infancy and now enters on the stage of vigorous youth." It is sincerely hoped that this " vigorous youth" will not, like so many others, be lost through the war. The officers and members of the American Rheumatism Association, having anticipated with great pleasure the opportunity of acting as hosts to the 1940 meeting of the International League, were deeply disappointed when it became necessary to cancel rather elaborate plans already made for the meeting, plans into which several of our oldest and largest medical and educational institutions. and the governments of the States involved had enthusiastically entered. It is tragic indeed that the fine co-operation expressed through the activities of the League must be temporarily suspended, but it is confidently expected that the general campaign and the activities of the League, though retarded by the war, will be renewed with increased vigour afterward, so that the hope of its sponsors may be realised; that perhaps within a decade the rheumatic diseases can be largely brought under control.

\section{REFERENCES}

1. Аввотт, W. D. (1938): Journ. Iowa Med. Soc., xxviii. 266-271.

2. Abrams, N. R., and Bauer, Walter (1938): J.A.M.A., cxi. 1632 . 1639.

3. Abramson, Harold, and Tunick, A. M. (1938): Journ. Pediat., xiii. 94-100.

4. Archer, B. H. (1938): New York State Journ. Med., xxxviii. 1177. 1182.

5. Atsatt, R. F. (1938): Urol. and Cutan. Rev., xlii. 262-263.

6. BARR, J. S. (1938): Surgery, iv. 1-12.

7. Bauer, Walter, and Coggeshall, H. C. (1938): Tr. Assoc. Amer. Physicians, liii. 318-319.

8. Bell, J. C., ANd Spurling, R. G. (1938): Radiology, xxxi. 473-480.

9. Bierman, William, and Horowitz, E. A. (1938): New England Journ. Med., ccxviii. 60-62.

10. Blatr, H. C. (1938): Surg., Gynec. and Obst., lxvii. 413-423.

11. Bland, E. F., And Jones, T. D. (1938): Arch. Int. Med., lxi. 161-171.

12. Boone, J. A. (1938): Amer. Heart Journ., xv. 119-122.

13. Boone, J. A., and Levine, S. A. (1938): Amer. Journ. Med. Sc., cxcv. 764-770.

14. Bowers, J. M. (1938): Northwest Med., xxxvii. 284-288.

15. Breuer, M. J. (1938): Nebraska State Med. Journ., xxiii. 361-365.

16. Burman, M. S. (1937): Acta rheumatol., ix. 10-12.

17. Butler, E. C. B. (1938): Clin. Journ., lxvii. 201-204.

18. Carpenter, C. M., Leahy, Alice D., and Wilson, K. M. (1938): Amer. Journ. Syph., Gonor. and Ven. Dis., xxii. 55-58.

19. Cavenagh, J. B. (1937): Journ. Laryng. and Otol., lii. 817-821. 
20. Cecil, R. L., and Angevine, D. M. (1938): Ann. Int. Med., xii. $577-584$.

21. Chamberlain, E. B., and Taft, R. B. (1938): Radiology, xxx. 761762.

22. Clawson, B. J., Noble, J. F., and Lufkin, N. H. (1938): Amer. Heart Journ., xv. 58-76.

23. Coburn, A. F., ANd Moore, Lucile V. (1939): Journ. Clin. Investigation, xviii. 147-155.

24. Cohen, Abraham (1938): Pennsylvania Med. Journ., xli. 1100-1104.

25. Cook, E. N., AND Buchtel, H. A. (1938): Minnesota Med., xxi. $546-550$.

26. Dawson, M. H., and Tyson, T. L. (1938): Tr. Assoc. Amer. Physicians, liii. 303-309.

27. Digilio, V. A., Pescatore, J. A., and Goldberg, H. E. (1938): Arch. Pediat., lv. 457-464.

28. Eigen, L. A. (1938): Amer. Heart Journ., xvi. 363-366.

29. Elkins, E. C., And Krusen, F. H. (1938): Proc. Staff Meet., Mayo Clin., xiii. 299-303.

30. Evans, Alice C., Robinson, F. H., and Baumgartner, Leona (1938): Pub. Health Rep., liii. 1507-1525.

31. Ferderber, M. B. (1938): Pennsylvania Med. Journ., xli. 354-357.

32. Fincher, E. F., ANd Walker, E. B. (1938): South. Surgeon, vii. 97-105.

33. Finkelstein, Harry, Greenberg, B. B., Jahss, S. A.. and Mayer, LeO (1938): J.A.M.A., cX. 480-483.

34. Friedman, Emanuel, and Stettheimer, C. J. (1938): Journ. Pediat., xii. 514-516.

35. Goldfain, N. (1938): South. Med. Journ., xxxi. 325-327.

36. Gouley, B. A. (1938): Amer. Journ. Med. Sc., cxcvi. 1-10.

37. Gray, Horace (1938): Internat. Clin. (s. 48), ii. 53-63; (s. 48) ii. 65-76; (s. 48) ii. 77-96.

38. Hall, F. C. (1938): New England Journ. Med., ccxix. 1015-1026.

39. Hedley, O. F. (1938): Pub. Health Rep., liii. 1635-1647.

40. Hedley, O. F. (1937): Pub. Health Rep., lii. 1907-1923.

41. Hench, P. S. (1938): Arch. Int. Med., lxi. 451-480, 495-500.

42. Hench, P. S. (1938): Proc. Staff Meet., Mayo Clin., xiii. 161-167.

43. Hench, P. S. (1938): Brit. Med. Journ., ii. 394-398.

44. Hench, P. S. (1938): "A Survey of Chronic Rheumatic Diseases," 1938. Oxford University Press, London, pp. 35-62.

45. Hench, P. S., Bauer, Walter, Dawson, M. H., Hall, Francis, Holbrook, W. P., Key, J. A., And McEwen, C. (1940): Ann. Int. Med. (In press; to appear in March and April.)

46. Herrell, W. E., and Brown, A. E. (1938): Proc. Staff Meet., Mayo Clin., xiii. 555-560.

47. INGE, G. A. L. (1938): J.A.M.A., cxi. $2451-2455$.

48. Jacobsen, Frances, Mason, H. C., and Arnold, Lloyd (1938): Journ. Lab. and Clin. Med., xxiii. 729-736.

49. Jacobson, B. M. (1938): Ann. Int. Med., xi. 1277-1295.

50. Jacoby, Adolph, Wishengrad, Michael, and Koopman, John (1938): Amer. Journ. Syph., Gonor. and Ven. Dis., xxii. 32-38.

51. Jones, T. B. (1938): Amer. J. Pub. Health, xxviii. 637-643.

52. Jordan, E. P. (1938): Arch. Path., xxvi. 274-288.

53. KaISer, A. D. (1938): New York State Journ. Med., xxxviii. 868-873 
54. KeIl, Harry (1938): Quart. Journ. Med. (n.s.), vii. 1-15.

55. KeIl, Harry (1938): Ann. Int. Med., xi. 2223-2272; Medicine, xvii. $261-380$.

56. Key, J. Albert, Rosenfeld, Herman, and Tuoflat, O. E. (1939): Journ. Bone and Joint Surg., xxi. 339-345.

57. Kovacs, R. (1938): Med. Rec., cxlvii. 61-65.

58. Kroner, Jacques, Lintz, R. M., Tyndall, Marion, Andersen, Leonora, and Nicholls, Edith E. (1938): Ann. Int. Med., xi 1077-1083.

59. Krusen, F. H., Randall, L. M., ANd Stuhler, L. G. (1938): Amer. Journ. Syph., Gonor. and Ven. Dis., xxii. 185-197.

60. Kunns, J. G. (1938): New England Journ. Med., ccxix. 516-520.

61. Lichtman, S. S. (1937): Journ. Mt. Sinai Hosp., iv. 72-76.

62. Lichtman, S. S. (1938): Ann. Int. Med., xi. 1992-1995.

63. Litchfield, H. R. (1938): Arch. Pediat., lv. 135-142.

64. Love, J. G., AND WALSh, M. N. (1938): J.A.M.A., cxi. 396-400.

65. Ludwig, A. O., Bennett, G. A., and Bauer, Walter (1938): Ann. Int. Med., xi. 1248-1276.

66. Masselu, B. F., ANd Jones, T. D. (1938): New England Journ. Med., cexviii. 876-878.

67. McEwen, Currier (1938): Arch. Path., xxv. 303-314.

68. McEwen, Currier, and Thomas, E. W. (1938): Med. Clin. North America, xxii. 1275-1286.

69. McIntire, F. T. (1938): Texas State Med. Journ., xxxiv. 22-27.

70. Melnick, P. J. (1938): Illinois Med. Journ., lxxiii. 336-339.

71. Meyer, Karl, Smyth, Elizabeth M., and Dawson, M. H. (1938): Science, lxxxviii. 129.

72. Meyerding, H. W. (1938): J.A.M.A., cxi. 1971-1976.

73. Morgan, J. E., ANd Webster, S. J. (1938): J.A.M.A., cx. 1744-1745.

74. Nicholls, Edrth E. (1938): New York State Journ. Med., xxxviii. 1218.1220.

75. Offenkrantz, F. M. (1938): Amer. Journ. Dis. Child., lvi. 67-82.

76. Osborne, S. L., Blatt, M. L., and Neymann, C. A. (1938): Physiotherapy Rev., xviii. 68-72.

77. Pemberton, R., and Scull, C. W. (1938): "A Survey of Chronic Rheumatic Diseases, 1938." Oxford University Press, London, pp. 107-125.

78. Poindexter, C. A., and Bruger, M. (1938): Arch. Int. Med., lxi. 714-719.

79. Poppen, J. L. (1938): S. Clin. North America, xviii. 879-887.

80. Portis, R. B. (1938): Amer. Journ. Dis. Child., lv. 1000-1017.

81. Prickman, L. E., Bennett, R. L., and Krusen, F. H. (1938): Proc. Staff Meet., Mayo Clin., xiii. 321-328.

82. Randall, L. M., Krusen, F. H., and Bannick, E. G. (1938): Amer. Journ. Obst. and Gynec., xxxvi. 230-235.

83. Rawls, W. B., Ressa, A. A., Gruskin, Benjamin, and Gordon, A. S. (1938): Ann. Int. Med., xi. 1401-1406.

84. Read, Frances E. M., Crocco, Antonio, and Taussig, Helen B. (1938): Amer. Journ. Hyg., xxvii. 719-737.

85. Reed, J. R., ANd Goldfain, E. (1938): Journ. Oklahoma Med. Assoc., xxxi. 302-304.

86. Rinehart, J. F., Greenberg, L. D., Baker, Frances, Mettier, S. R., Bruckman, F., ANd Choy, Frank (1938): Arch. Int. Med., lxi. 537-546. 
87. Rinehart, J. F., Greenberg, L. D., Olney, Mary, and Choy, FranK (1938): Arch. Int. Med., lxi. 552-561.

88. Rock, J. H. (1938): Med. Bull. Vet. Admin., xv. 13-15.

89. Sako, Wallace, Dwan, P. F., and Platou, E. S. (1938): J.A.M.A., cxi. 995-997.

90. Schein, A. J. (1938): Arch. Int. Med., lxii. 963-978.

91. Schmid, W. H. (1938): Arch. Phys. Therapy, xix. 457-462.

92. Schnabel, T. G., and Fetter, Ferdinand (1938): Amer. Journ. Syph., Gonor., and Ven. Dis., xxii. 39-47.

93. Schroder, C. H. (1938): Minnesota Med., xxi. 322-325.

94. SHerwood, K. K. (1938): Northwest Med., xxxvii. 288-289.

95. Simmons, E. E., AND Dunn, F. L. (1938): Nebraska Med. Journ., xxiii. 451-452.

96. Sмттн, С. B. (1938): West Virginia Med. Journ., xxxiv. 111-114.

97. Smith, D. W., Blocker, T. G., ANd Tumen, H. J. (1938): Journ. Florida Med. Assoc., xxiv. 586-596.

98. Soto-Hall, RalPh (1938): Ann. Surg., cviii. 124-126.

99. Steinberg, C. L. (1938): Journ. Lab. and Clin. Med., xxiv. 17-24.

100. Sutton, Lucy P., ANd Dodge, Katharine G. (1938): Journ. Pediat., xii. 490-492.

101. SwetT, P. P. (1938): Journ. Bone and Joint Surg., xx. 68-76.

102. Swirt, H. F., MoEn, J. K., ANd Hrrst, G. K. (1938): J.A.M.A., cx. 426.434.

103. TalbotT, J. H., AND Coombs, F. S. (1938): J.A.M.A., cx. 1977 1982.

104. TARSY, J. M. (1938): Med. Rec., cxlviii. 269-272.

105. TAussig, A. E. (1938): Journ. Lab. and Clin. Med., xxiii. 833-838.

106. Terhune, S. R. (1938): Journ. Med. Assoc. Alabama, vii. 255-256.

107. Thomas, Caroline B., and France, Richard (1939): Bull. Johns Hopkins Hosp., lxiv. 67-77.

108. Thompson, H. E., and Wyatt, B. L. (1938): Arch. Int. Med., lxi. 481-500.

109. Thompson, H. E., AND WyatT, B. L. (1938): Journ. Kansas Med. Soc., xxxix. 327-330.

110. Thompson, H. E., Wyatt, B. L., and Hicks, R. A. (1938): Ann. Int. Med., xi. 1792-1805.

111. Traut, E. F., and Logan, Catharine E. (1938): J.A.M.A., exi. 1092-1093.

112. Trautman, J. A., Stroupe, H. V., and Devlin, D. J. (1938): Amer. Journ. Syph., Gonor. and Ven. Dis., xxii. 48-54.

113. Trimble, H. C., and Keeler, C. E. (1938): Journ. Heredity, xxix. 281-289.

114. United States Public Health Service (Bulletin No. 4) (1938): 20 pp.

115. Vonderlehr, R. A., ANd Usilton, Lida J. (1938): Amer. Journ. Syph., Gonor. and Ven. Dis., xxii. 537-543.

116. Vorhaus, M. G., and Kramer, M. L. (1938): Tr. Amer. Therap. Soc., xxxviii. 109-115. See also: Science, 1937 (Suppl.), lxxxv. 10.

117. Welch, Henry, Wentworth, J. A., ANd Mickle, F. L. (1938): J.A.M.A., exi. 226-231.

118. WHITE, T. P. (1938): South. Med. and Surg., c. 63-65.

119. Willirus, F. A., AND DRY, T. J. (1938): Internat. Clin. (s. 48), iii. 39.46. 